\title{
ATTITUDES OF THE ESTONIAN BORDER GUARD AND POLICE OFFICERS ON IMMIGRATION AND RADICALIZATION
}

\author{
Kai Veispak-Rawlings \\ Lecturer, Estonian Academy of Security Sciences, \\ e-mail: kaiveispak@gmail.com, Tallinn, Estonia
}

\begin{abstract}
The article in the first part outlines the current discussion of the state of training under cultural intelligence, including definitions and examples of possible interdictions of the bad players. The second part describes the attributes and attitudes of Border Guard and Police officers after cultural intelligence courses, defining and applying the concepts towards internal security with a focus on Cultural Identity, "what makes a person tick." An empirical study consisting of written reports was conducted over a three-year period and compiled to reflect attitudes towards immigration and radicalization in the EU.
\end{abstract}

Keywords. Asylum seekers, Border Guard Officers, cognitive dissonance, cognitive intelligence, CQ, Cultural Identity, Cultural intelligence, immigration, Internal Security, Islamic terrorists, language learning, lone-wolf, migration, open borders, Police Officers, political correctness, radicalization, Schengen Treaty, terrorists.

\section{Introduction}

With the critical and fast-changing paradigms surrounding immigration, migration, open EU borders, visa-free agreements, religious tolerance, political correctness, workplace inequality and many other issues that relate to internal security, the aim and purpose of this article is to report on the attitudes and views of Border Guard and Police Officers in Estonia towards immigration and radicalization of immigrants. Empirical research was conducted over three years where respondents were asked to write a report of their attitudes and views on immigration and/or radicalization based on their current knowledge, salient factors, current and best practices and cultural norms that security officers can use to increase their understanding of, tolerance for, or non-tolerance of, immigrants and tourists. The author has been a lecturer on this topic for the past seven years, discovering and tackling the issues of how cultural intelligence (CQ) can be applied to the field of Internal Security. But the topic is just being formed and, in its infancy, with many studies and research projects needing to take place to form the major points, the correct definitions, and the primary bullets, so this empirical study was conducted to establish attitudes and norms with a goal to help to enhance and support Internal Security measures.

The second part of this article is a report on the current attitudes compiled from 147 essays, written by a variety of active Estonian Border 
Guard and Police officers and cadets of the Estonian Academy of Security Sciences.

\section{Part 1 \\ 1. Background}

With millions of immigrants pouring into the EU from war-torn and economically devastated countries, leaders are grappling with many new problems brought about by increased cultural divergence. Media headlines such as "Identifying killers in a sea of suspects" in a recent issue of The International New York Times focuses on the problem of immigrants in view of the Orlando gay club shootings (Callimachi, 2016). One example used in the article describes the French terrorist Larossi Abbalia, who was convicted on a terrorism charge. The investigators viewed a video, captured on the suspect's mobile phone, which showed his group killing rabbits in Northern France, two years before his crime of killing a French couple with a knife. When the investigators questioned the suspect, he informed them that he was an atheist, that the group killed rabbits, not to learn the art and feel of killing, but in order to have halal meat to eat during the Islamic holiday, Eid-al-Adha. ${ }^{1}$ The investigators did not know or discover until later that the holiday had taken place two months before in November, while the video was made in January.

The BREXIT campaign vote to leave the EU was passed with a majority of voters declaring immigration was the big problem and why they voted to leave the Union. "The vote by Britons on June 23, 2016, to leave the European Union doubled as a referendum on how the country views the issue of immigration," said Josh Siegel in The Daily Signal (Siegel, 2016). On December 12, 2019, UK voters elected a conservative government with a massive 80 seat majority with the goal to leave the EU. Immigration was a major topic in the news with reports of problems with immigrants and illegal crossings into the UK which is reflected in the results of the referendum.

Educational leaders are now grasping with the concepts of adding curricula under the CQ umbrella and providing cultural sensitivity training to security officers, worried about the political and economic ramifications resulting from mistakes made through ignorance of cultural laws and norms and adjusting rules and laws to administer and manage the influx of culturally divergent migrants. Past curricula have focused on language learning as a primary tool in the cultural intelligence framework, with a

\footnotetext{
${ }^{1}$ Eid al-Adha, also called the "Festival of the Sacrifice", honors the willingness of Ibrahim (Abraham) to sacrifice his son as an act of obedience to God's command. But, before Abraham could sacrifice his son, God provided a goat to sacrifice instead. In commemoration of this intervention, an animal is sacrificed ritually and divided into three parts. One share is given to the poor and needy, another is kept for home, and the third is given to relatives.
} 
little-added education on religious diversity.

Asking the question, "Is it legal in the EU to strip search a Muslim woman?" to a classroom of thirty border guard officers from Latvia, Lithuania, Poland, and Estonia, only two answered correctly, that it is legal.

\section{Cultural intelligence (CQ)}

Cultural intelligence (CQ) is defined as a person's capability to function effectively in situations characterized by cultural diversity (Ang, Van Dyne \& Koh, 2005; Earley \& Ang, 2003; Earley \& Mosakowski, 2005). Culture is typically described as the totality of learned behaviors of people that emerge from their interpersonal interactions. Culture includes the ideals, values, and assumptions about life that are widely shared and that guide specific behaviors. Objective culture is visible: artifacts, food, and clothing. Subjective culture is invisible: values, attitudes and norms (Brislin, 2001). Intelligence, as defined in a contemporary concept, recognizes that intelligence is more than cognitive ability (Sternberg \& Detterman, 1986). "For example, research recognizes the importance of interpersonal intelligence, emotional intelligence, and social intelligence. Like these other forms of intelligence, CQ complements IQ (cognitive intelligence) by focusing on specific capabilities that are important for high-quality personal relationships and effectiveness in culturally diverse settings (Sternberg \& Detterman, 1986)."

From the Harvard Business Review, "Occasionally an outsider has a seemingly natural ability to interpret someone's unfamiliar and ambiguous gestures in just the way that person's compatriots and colleagues would, even to mirror them. We call that cultural intelligence or $C Q$. In a world where crossing boundaries are routine, CQ becomes a vitally important aptitude and skill, and not just for international bankers and borrowers."(Earley \& Mosakowski, 2004, p. 139). Reputable international business institutions that have only added CQ courses to their curricula in the last decade have set their focus only on conducting business in the international marketplace teaching students what to do and what not to do with proper etiquette, how to gain trust and most importantly, how to understand what the foreign person is really saying, reading their body language and understanding their gestures for clues?

The question arises as to what and how much of CQ can be applied to cross-border and internal security. The facts are:

- There is widespread globalization with people of different cultures living and working together everywhere in the world.

- There are more opportunities for officers to interact with foreigners in many aspects (e.g., domestically, business, and 
work).

- Officers need to know the customs of other cultures, especially the taboos, or they will risk offending people.

- Officers with higher CQ could be able to interact with people from other cultures easily and more effectively.

\section{Under the umbrella of CQ comes Cultural Identity (CI)}

Cultural Identity (CI) is the primary marker of who a person is. This can be defined as who or what they identify with. The quick and first answers range from religion (I am a Christian), political parties (I am a Socialist), Nationalism (I am Estonian), groups (I am a skinhead) to philosophical or social answers (I am a free thinker; I am independent; I consider myself a sovereign person).

Some problems can emerge when tackling the irreducibility of the concept of Cultural Identity. CI turns out to be one of the least wellunderstood concepts. Stuart Hall and Paul Du Gay stated, "It is drawing meanings from both the discursive and the psychoanalytic repertoire, without being limited to either. In common sense language, identification (CI) is constructed on the back of a recognition of some common origin or shared characteristics with another person or group, or with an ideal, and with the natural closure of solidarity and allegiance established on this foundation. In contrast with the 'naturalism' of this definition, the discursive approach sees identification as construction; a process never completed - always in process." (Du Gay \& Hall, 1996)

There can be many parameters, categorizations, or identifiers to a person's CI. A person's self-perception can be related to nationality, ethnicity, religion, social class, generation, locality or just about any group with its own distinct culture. Paul James defined categorizing CI as "categorizations about identity, even when codified and hardened into clear typologies by processes of colonization, state formation or general modernizing processes, are always full of tensions and contradictions. Sometimes these contradictions are destructive, but they can also be creative and positive." (James, 2015, p. 174-196). A person may associate with many identities. Their first answer to a question is usually their most prominent identifier. The concept of identification inherits a rich semantic legacy. Freud calls it "the earliest expression of an emotional tie with another person." (Freud, 1991).

The personal identity of an individual is the key to interdiction. If an officer had the opportunity to interview Matteen, the Orlando shooter, two weeks before the event, would he or she have identified the risk factors? Could they have understood his radicalization, his internal cognitive 
dissonance?

Leon Festinger (1957) proposed his cognitive dissonance theory, which states that a powerful motive to maintain cognitive consistency can give rise to irrational and sometimes maladaptive behavior.

According to Festinger, we hold many cognitions about the world and ourselves; when they clash, a discrepancy is evoked, resulting in a state of tension known as cognitive dissonance. As the experience of dissonance is unpleasant, we are motivated to reduce or eliminate it and achieve consonance (i.e., agreement) (McLeod, 2014).

Festinger's (1957) cognitive dissonance theory suggests that we have an inner drive to hold all our attitudes and beliefs in harmony and avoid disharmony (or dissonance). If not, they explode into violence. A welltrained interdiction Officer with a high CQ, maybe could have picked up the clues of Matteen's cognitive dissonance if given the opportunity and saved lives.

\section{Can internal security benefit from CQ education?}

The answer is probably yes. It follows from the statement that, any officer who better understands the person being questioned is better able to determine and carry out the correct procedure. Someone standing in the airport line, sweating and looking nervous, is an obvious clue there is something wrong. If that person is also wearing a headscarf, does the attitude of the officer change?

Can an officer: 1 . Strip search a person wearing religious clothing, such as Muslims, Hindus, and Mormons? 2. Require a practicing Jew in prison to do mechanical work during Shabbat? 3. Keep a Muslim in detention from praying five times a day?

If an officer knows the correct answers to these types of questions, then it can help make it easier to communicate and may defuse what could turn into a major incident at a border crossing point or any other interdiction of migrants or tourists.

While an officer cannot disarm their foreign guests simply by showing they understand their culture or identity, their actions and questions can help prove that they have already, to some extent, entered into their world, which in turn can open them to more truthful responses. It can simply be in the way the officer shakes hands, orders coffee, or nods the head, ready evidence of the ability to mirror the customs and gestures of the migrant or foreign visitor. With a welcome demeanor and a familiar gesture, an officer can create a more trusting and open atmosphere.

How can understanding a personal identity lead to knowledge of a person's intent to do harm? What makes a person tick? How does a Muslim 
become radicalized? These vast questions are looming more significant, and answers are slowly being formed. The debate in the USA over what to label Omar Matteen, the perpetrator of the shooting at the gay night club in Orlando, is an example of the confusion. Some politicians and academicians label him as disturbed, from an "unhinged home" (Harris, Zadrozny \& Zavadsky, 2016) while others simply label him as an Islamic Terrorist. He was born and raised in the USA, but the portrait painted of him by The Daily Beast, depicts a troubled kid that never assimilated into the American culture with multiple examples of domestic strife, struggles in school because of his lack of English language skills, and frequent outbursts of violence. His father supported the Taliban. What causes the radicalization of a first, second or third-generation immigrant? Many academicians and security experts are struggling to answer this question.

Would officers need to pass in-depth studies in history, religion, and world affairs to begin to put a man like Matteen on their radar? Would they also need to understand the psychology of human behavior in terms of assimilation into a new culture?

While the answers to these questions can seem daunting, there are some clues from the curricula of the new International business courses that are springing forth from the prominent Universities. The courses teach students to learn some details of the homeland of the person they are about to meet. Then make a comment about the person's homeland, which can be an icebreaker that leads to better business relations. Turning this concept into a security aspect, if the person presented what appears to be a false Turkish passport to a border officer, a question about a geographical location in Turkey could possibly ascertain if they are Turkish or not? If the officer has learned some simple geographical facts about Turkey, can they then, in an informed method, question the person and possibly reveal the truth?

\section{Salient Subject Categories that form a personal identity}

Geography - Where a person is from, do they identify with that location, what are some strategic identifiers of their location, what are some historical facts, famous figures, monuments, rivers, mountains, what ethnic groups exist there, and what is the current population?

Nationality - Is a Caucasian a white person from America or a person from Georgia?

Race - White, black, brown, mixed etc.

Language - What language is spoken in the native tongue, other languages, what dialect of that language is used, what is the origin of the language, what other countries speak it? 
Religion - What are the key aspects that establish a personal identity with a Christianity, Islam, Scientology, Mormonism, Judaism, Shintoism, Zoroastrianism, etc., and sub-groups, Shi'ism, Holy Rollers, etc.

Social - Gamer, sports, opera, journalist, priest, wine connoisseur, chef, writer, traveler, etc.

Gender/sexual orientation - Male, Female, Transgender male, Transgender female, gay, straight.

Food and drink - Partake or not in pork, fish, animal products, coffee, milk, milk with meat, alcohol, vegetarian, or vegan.

Political - Socialist, capitalist, Nazi, Fascist, Sovereign.

Economics/Class - Financial capacity, rich, poor, Indian caste system. or fear.

Physical - Hand and head gestures, personal space, smiling, frowning,

\section{Conclusions of Part 1}

Can an officer with a higher CQ be better at their work of interdiction, and then can they also be more respectful of those who have no criminal intentions? Developing a higher CQ is a lifelong task with much knowledge to be learned and gained in many diverse areas. No officer can know everything that could be covered in a CQ curriculum as the mass of knowledge is extensive and infinite. However, can a little bit of CQ knowledge go a long way in helping to create an atmosphere of openness during an interdiction? Sometimes the most obscure knowledge could be the key to a successful interdiction of the bad guys. As in the case of the French terrorist, Larossi Abbalia, if an officer would have known he was a liar, by knowing when the Eid holiday occurred, it is possible he would not have been let out of their grasp to murder a young French couple.

\section{Part 2}

\section{Questions}

Two different tasks were posed to different target respondents. 1 . Write a short essay on your views of radicalization; 2 . Write a short essay on your views on immigration. The research was conducted as a final review after the completion of Cultural Intelligence as outlined and provided in the background above. There was a total of 147 respondents. The essays were submitted anonymously

\section{Focus}

The focus of the research was to create a basis of material on which 
analysis of the concepts could be performed on radicalization and immigration to enhance future training concepts. The following questions can then be answered. 1. Are the attitudes of Border Guard and Police Officers on radicalization and immigrating as applied to Internal Security in need of reform? 2. Do the attitudes of Border Guard and Police Officers towards immigrants allow for the interdiction of finding the 'bad people' and at the same time, once a foreign person is deemed "not bad", to treat the person with dignity and care?

\section{Overall attitude of respondents}

The essays were generally polite and respectful, with most respondents displaying acceptance to immigration as a norm and to be addressed with a high level of professionalism. For radicalization, many reasons were put forward as to the causes and not so many of how to stop it.

The calculated summary of respondents:

- Radicalization was mainly seen as associated with Islam - 58 respondents.

- Immigration was seen as leading to radicalization - 24 respondents.

- The majority of respondents, 97 , were able to see immigration as both positive and negative (radicalization, conflicts with locals, jeopardizing the preservation of the local culture and identity versus helping people in need, providing more workforce, expanding experiences, etc.)

- 25 respondents saw immigration as negative and were completely against it.

- 23 respondents considered immigration a totally positive and natural phenomenon, giving people more opportunities and providing a better life for those in need.

\section{Samples of Respondents on Immigration}

- On the one hand, you sympathize and want to help refugees and people seeking a better life. At the same time, however, you see the risks that excessive immigration can bring. Such, as creating their own community, where our rules and laws do not apply, and radicalization, because they cannot embrace another culture. However, I personally think that every person deserves the opportunity to change their lives for the better, and sometimes it is difficult to do this in their own country, where there is a war 
situation or a difficult economic situation.

- As Estonia spends money on refugees and their maintenance, it is essential to ensure that individuals adopt Estonian culture, language, history, customs, traditions. For this, give refugees, for example, a 2-year deadline for passing the Estonian language and culture test. Otherwise, they will be subject to immediate return to their country of origin. If you follow these steps and more, like constant surveillance and placement in specific areas to prevent the emergence of enclaves, then I think we and the immigrants can live with each other, and Estonia will benefit by gaining more labor.

- What do I think about immigration? My most honest answer is NO, please NO, no need. In my opinion, my reasoning and understanding are perfectly logical and understandable. If you look at refugee migration from the point of view of a policeman, you would say thank God that Estonia is not a welfare state. THANK GOD. It is clear that the Estonian state is not able to control the masses of refugees and immigrants such as those in Sweden, Germany, etc. Fortunately, to my knowledge, Estonia only has currently about 100. Reported in the news, internet, and newspapers, how life and security in Vao has turned worse by 180 degrees. Local children cannot play and be with refugee children, Vao village refugees' gang-raped a woman from the village.

- I just want to say that if a person really needs help, they are also grateful for that help. Of course, everything that we take for granted in our society may not be understandable to someone from a completely different cultural space. Nevertheless, a compromise must be found in which the individual should consider whether safe life of him and his family are important to him, or will he prefer the habits that do not seem acceptable to him. The concept of convenience should not be included in the context of migration. It only brings bad things. Society will begin to look at the whole issue of migration from just one angle, and call all of them refugees of convenience, forgetting all the people who really need help.

- I would like to help people while mass immigration is happening is not good. I don't think many would object to a refugee family moving in somewhere, but there were statistics that showed that most refugees are young men, and there are few women. In the end, there may be so many (and some places there already are).

- I am a tolerant person, but at the same time, I am against it rather than in favor. This situation is already critical in Europe. If you really offer people a place to live, the process should be extra careful as in who to give it and not to let them in en masse. 
- Immigrants from third countries may form groups, live, and behave in ways that are customary to their cultural space, often in a way that we cannot perceive as tolerable (such as corporal punishment).

- I think people in my country's territory, culture, people must be protected. Therefore, mass migration from third countries (even considering their cultural specificities) is not very good for any European country.

- $\quad$ During my service, I have noted that many foreigners are able to learn the Estonian language even in 1 to 2 years and can express their thoughts and communicate in Estonian. For me, it is absolutely amazing how an Arabic speaker, for example, learns the language so quickly and wants to fit in with our society. Unfortunately, there are stateless persons in the country, as well as children with Estonian citizenship who do not know and do not want to learn the official language, I do not understand it at all.

- Unfortunately, there is a downside, as the laws in different countries are different people coming from these countries tend to break the rules of the law and commit different offenses. For example, a male Islamic religious man would beat his wife at home, and for him, it was perfectly normal as no one explained to him that this was not accepted in our society.

- As a future police officer, I consider internal security to be of the utmost importance and, whether they like it or not, not all people who seek asylum are with good intentions. And the reality is that of all those who want to move to another more prosperous country, only 10\% of people really need help. But I think it is our duty to help just that 10\%, while at the same time ensuring the internal security of us and the other Schengen countries.

- $\quad$ For me, in the big picture, immigrants are divided into two: people in real need for help (such as war refugees) and illegals (those moving to pull centers and seekers for a better life).

- To sum up, if someone asks me if I would allow people into the country, I think women and children are not a security threat. The danger is for young men who should fight for their families in the war and not come to exercise their power in a foreign country. However, since our cultures are too different, and these people are not able to adapt to our society, I would not allow them into my country.

\section{Samples of Respondents on Radicalization}

- $\quad$ Radicals have also begun to be linked to extremist religions who 
impose their will on others by force or by political persecution. One of them is radical Islam. Where radical Islam begins is different for every individual and bound to everyone's tolerance limits, but terrorist Islam can be said to be radical. Radical Islam has become a dominant part of Europe as a whole since terrorism worldwide has its roots in radical Islamic countries that tend towards Islamic sects.

- $\quad$ Radical Islam has become a dominant part of Europe as a whole, since terrorism worldwide has its roots in radical Islamic countries that tend towards Islamic sects. Representatives of such sects, in turn, recruit religious brethren from mosques and other circles to fulfill the call of the Imam, either as suicide bombers or simply as organizers.

- London's chief Imam and great prophet and leader has said 11 years ago: All Muslims must become fighters in the new battle. Europeans must understand that it is pointless to fight people who crave death and whose death means victory. Death for God is as old in the Islamic world as the Islamic faith itself.

- In my mind, and in the opinions of many other people, it is impossible to establish democracy in the Middle East at this time given the cultural background and customs of this population. In order for radicalism not to start, it is necessary to take account of all social groups and, if possible, to eradicate the intolerant ones. In any case, the ultimate eradication of radicalism is impossible.

- $\quad$ For example, when it comes to parties that are very radical and have extreme views, in this case people can only blame themselves for electing such people.

- As far as the reaction to radicalization is concerned, my view is that there is no direct need to respond to its verbal manifestations - the only idea to do so would be to develop a discussion for which people with radical views are not ready anyway. However, one must definitely respond to actions and calls arising from radical views, which pose a real threat to national security. In such cases, the security authorities must react.

- I have nothing against people who believe in something, but these people cannot impose their beliefs and principles on others or kill innocent people with it.

- $\quad$ Radicals are latent and dangerous individuals with their own political views, ready to go till the end. Social and regional inequalities exacerbate the problem in a stratified society. With radicalization, minorities are trying to survive.

- In the case of radicalization, radicalization is very worrying and a major problem, especially among young people. It is important that 
the most vulnerable and vulnerable part of society, young people, would be noticed in a timely manner by those who contribute to their self-esteem, the ability to be an equal part of society, regardless of cultural background, religion, sexual orientation, physical background and economic situation.

\section{Conclusions}

The attitudes of respondents did not undergo drastic change throughout the courses of instruction. The cadets and officers obtained more in-depth knowledge of cultural differences, and more self-awareness of their role in immigration issues. The sample quotes above are direct answers to the questions leaving out the comments on how the classes helped the students to become more aware of the social and cultural differences. The students rated the classes very high in terms of raising awareness and expressed interest in further classes to increase their knowledge on the subject. However, those opposed to immigration remained opposed and those with a favorable attitude kept their views but revealed that more could be done to help with the problems created by immigrants. Cheap labor was deemed a positive by most, but this was often countered by most respondents citing the problems to society as being more significant than any potential benefits to the economy.

The answers to the two main questions posed is that it became apparent to the author that gaining more knowledge of the backgrounds and culture of immigrants is the main key to respect and tolerance, and very helpful and instrumental in the role of interdiction and national security. However, personal attitudes are preconceived and mostly formed from outside factors. More knowledge of customs and culture, while helpful in their daily work, can only change them slightly.

\section{References}

1. ANG, S., \& EARLEY, P.C. (2003). Cultural intelligence: Individual interactions across cultures. Stanford University Press

2. ANG, S., KOH, C., \& VAN DYNE, L. (2006). Personality Correlates of the FourFactor Model of Cultural Intelligence Article. Group \& Organization Management 31(1), February, p. 100-123.

3. BRISLIN, R.W. (2001). Understanding Culture's Influence on Behavior (PSY 399 Introduction to Multicultural Psychology). 2nd edition, Wadsworth

4. CALlimACHI, R. (2016). Attacks Expose a Struggle To Spot Future Terrorists. International New York Times. June 22.

5. DETTERMAN, D., \& STERNBERG, R. (1986). What is intelligence? Contemporary viewpoints on its nature and definition. Norwood, NJ, Ablex 
6. DU GAY, P., \& HALL, S. (1996). Questions of cultural identity. Sage Publications, Inc.

7. EARLEY, P.C., \& MOSAKOWSKI, E. (2004). Cultural Intelligence. Harvard Business Review, 82, p. 139-153.

8. FREUD, S. (1991). Group Psychology and the Analysis of the Ego. Civilization, Society and Religion. London, Penguin Books. Vol. 12, Penguin Freud Library, p. 91-178

9. HARRIS, S., ZAVADSKY, K., \& ZADROZNY, B. (2016). House of Horrors - The unhinged home that raised Orlando killer Omar Matteen. Retrieved August 10, 2020, from https://www.thedailybeast.com/the-unhinged-home-that-raisedorlando-killer-omar-mateen

10. JAMES, P. (2015). Despite the Terrors of Typologies: The importance of Understanding Differences and Identities. Interventions: International Journal of Postcolonial Studies. Vol. 7 (2), p. 174-195.

11. MCLEOD, P. (2014). Cognitive Dissonance. Retrieved August 10, 2020, from https://www.simplypsychology.org/cognitive-dissonance.html

12. SIEGEL, J. (2016). The Daily Signal. June 23. Retrieved August 10, 2020, from https://www.dailysignal.com/ 